\title{
Thoughts on Psychoanalysis Today
}

\section{Molly S Castelloe*}

Interdisciplinary Studies Program, University of Connecticut, USA

Keywords: Transference; Counter-transference; Enactment; Gender; Erotic; Freud; Psychoanalysis

Zografia Andoniadou describes well how experiences of childhood and the unconscious conflicts arising from them become the focus of psychoanalytic therapy. I want to add that it is through the dynamics of transference and counter-transference that these childhood experiences, the pain and pleasure of them, come to light within this therapeutic relationship. Transference is the patient's emotional and erotic investment in the analyst; counter-transference is the analyst's corresponding investment in the patient. In this exchange, this mutually shared field of feeling, a new experience of human relating is created for the patient. Aided by the analyst's perspective, the analysand is able to relive his or her past with enhanced understanding and thus become freer of it.

Major changes infuse the profession since Freud even though his basic concepts endure. Transference is understood to occur as a part of the total analytic situation, co-created by both analyst and analysand. Inevitably transference and countertransference are intertwined. Furthermore, both individual psyches generate an intersubjective experience that Thomas Ogden calls the analytic third; the two subjectivities are also remade through this encounter with the third. Sometimes transference and counter-transference forces spill over into actions that the current practice of psychoanalysis recognizes as "enactments." These are little dramas produced by the unconscious wishes and fantasies of both analyst and patient. Sometimes subtle and hardly discernable, enactments provide rich material for interpretation or shared reflection.

Our understanding of gender has changed dramatically since the times of Victorian Europe: both sexes, male and female, have active and passive drives. The Preoedipal phase between mother and child has taken on a more prominent role of inquiry in research and in clinical practice, giving merited attention to the importance of this first interpersonal bond. Hopefully the maternal nourishment of the child has various dimensions; it is both a literal feeding and an emotional one. In other words, it is not just milk received by the baby, but also loving care, sweetness. Have you ever seen an infant trying to feed their mother? Humans have an innate desire to give back for the love they have received. This is a fortunate repetition compulsion. We have an instinct for affection that leads us to identify with the nurturer, as well as the aggressor.

While there may not always be "full confidence in treatment" the relationship should, in essence, be a trusting alliance. But moments of distrust, if brought into words, can be useful, too, in illuminating how the patient's history constricts their relationships in the present. Free association, dreams, fantasy, and slips of tongue are all clues to the ways we are moved around in the world through unconscious forces. While these revealing signs are interpreted by the analyst, the patient remains the ultimate judge of the accuracy of the interpretation and arbiter of his or her own living truth.

Optimally, the analyst is able to observe his or her own associations and emotional responses in detached manner during sessions, as if watching his or her own thoughts float down a stream. Attention to this internal reverie during clinical work is a fruitful source of understanding the patient, of making insightful interpretations and thus bringing knowledge to the patient's habits of intimacy and their way of relating to others.

I disagree with Andoniadou's suggestion; an assumption held by many, that psychoanalysis requires exorbitant cost. My late analyst once told me that this is one of the greatest resistances to psychoanalytic treatment: many training institutes have sliding scales. 